\title{
Research Upregulation of CD23 (FcERII) Expression in Human Airway Smooth Muscle Cells (huASMC) in Response to IL-4, GM-CSF, and IL-4/GM-CSF
}

\author{
Joseph T Belleau ${ }^{\dagger}$, Radha K Gandhi†, Holly M McPherson and D Betty Lew*
}

Address: Department of Pediatrics, Children's Foundation Research Center at the Le Bonheur Children's Medical Center, University of Tennessee Health Science Center, 50 North Dunlap Street, Rm401, WPT, Memphis, TN 38103, USA

Email: Joseph T Belleau - jcbelleau@yahoo.com; Radha K Gandhi - rgandhi@utmem.edu;

Holly M McPherson - HMCPHERSON@PIEDMONTALLERGY.COM; D Betty Lew* - dlew@utmem.edu

* Corresponding author †Equal contributors

Published: 20 May 2005

Clinical and Molecular Allergy 2005, 3:6 doi:10.1 186/1476-796/-3-6
Received: 30 August 2004

Accepted: 20 May 2005

This article is available from: http://www.clinicalmolecularallergy.com/content/3/I/6

(c) 2005 Belleau et al; licensee BioMed Central Ltd.

This is an Open Access article distributed under the terms of the Creative Commons Attribution License (http://creativecommons.org/licenses/by/2.0), which permits unrestricted use, distribution, and reproduction in any medium, provided the original work is properly cited.

\begin{abstract}
Background: Airway smooth muscle cells play a key role in remodeling that contributes to airway hyperreactivity. Airway smooth muscle remodeling includes hypertrophy and hyperplasia. It has been previously shown that the expression of CD23 on ASMC in rabbits can be induced by the IgE component of the atopic serum. We examined if other components of atopic serum are capable of inducing CD23 expression independent of lgE.
\end{abstract}

Methods: Serum starved huASMC were stimulated with either IL-4, GM-CSF, IL-I3, IL-5, PGD2, LTD4, tryptase or a combination of IL-4, IL-5, IL- I 3 each with GM-CSF for a period of $24 \mathrm{~h}$. CD23 expression was analyzed by flow cytometry, western blot, and indirect immunofluorescence.

Results: The CD23 protein expression was upregulated in huASMC in response to IL-4, GM-CSF, and IL-4/GM-CSF. The percentage of cells with increased fluorescence intensity above the control was $25.1 \pm 4.2 \%$ (IL-4), I $15.6 \pm 2.7 \%$ (GM-CSF) and $32.9 \pm 13.9 \%$ (IL-4/GMCSF combination)( $n=3$ ). The protein content of IL-4/GMCSF stimulated cells was significantly elevated. Expression of CD23 in response to IL-4, GM-CSF, IL-4/GM-CSF was accompanied by changes in cell morphology including depolymerization of isoactin fibers, cell spreading, and membrane ruffling. Western blot revealed abundant expression of the IL-4R $\alpha$ and a low level expression of IL-2R $\gamma c$ in huASMC. Stimulation with IL-4 resulted in the phosphorylation of STAT- 6 and an increase in the expression of the IL-2R $\gamma \mathrm{c}$.

Conclusion: CD23 on huASMC is upregulated by IL-4, GM-CSF, and IL-4/GM-CSF. The expression of CD23 is accompanied by an increase in cell volume and an increase in protein content per cell, suggesting hypertrophy. Upregulation of CD23 by IL-4/GM-CSF results in phenotypic changes in huASMC that could play a role in cell migration or a change in the synthetic function of the cells. Upregulation of CD23 in huASMC by IL-4 and GM-CSF can contribute to changes in huASMC and may provide an avenue for new therapeutic options in asthma targeting ASMC. 


\section{Background}

Chronic inflammation and airway smooth muscle dysfunction are consistent features of asthma responsible for disease progression and airway remodeling [1]. The increase in bronchial smooth muscle, both hypertrophy [2] and hyperplasia [3], plays a critical role in the development of airway hyperreactivity (AHR), the hallmark of asthma. Airway smooth muscle cells (ASMC) may also play a secretory or immunomodulatory role by producing pro-inflammatory cytokines, chemokines, polypeptide growth factors, extracellular matrix proteins, cell adhesion receptors, and co-stimulatory molecules, which perpetuate submucosal inflammation $[4,5]$. These mediators may act on the ASM itself in an autocrine manner as well to further contribute to the asthma phenotype [6]. Therefore, smooth muscle itself may be capable of initiating and maintaining airway inflammation. Also, ASMC have been shown to undergo cell migration, which could contribute to airway remodeling [7]. Thus, regulation of airway smooth muscle hypertrophy and migration may be a new target for treatment of asthma $[7,8]$.

It is well known that IgE plays a critical role in the pathogenesis of asthma in the early and late phases by interacting with its two receptors, the high affinity receptor (FceRI) and the low affinity receptor (FceRII) [9]. IgE plays a key role in bronchial hyperresponsiveness and smooth muscle hyperreactivity [8]. Crosslinking of the high affinity IgE receptor (FceRI) on mast cells leads to cellular degranulation and the release of various proinflammatory mediators and cytokines contributing to bronchoconstriction. The low affinity IgE receptor (CD23) (FceRII) has been identified on B cells, monocytes, follicular dendritic cells, Langerhan's cells, eosinophils, and platelets [10]. Upregulation of the CD23 receptor is thought to increase allergic responses in the bronchial mucosa through the enhancement of antigen uptake and presentation [8]. The receptor has two isoforms that differ only in their cytoplasmic domains [11]. CD23a is constitutively expressed on B cells and is associated with endocytosis of IgE coated particles, and CD23b is induced by IL- 4 and is also found on non- B cells such as T cells, Langerhan's cells, monocytes, macrophages, platelets, and eosinophils $[12,13]$. IL4 causes CD23 induction on B cells through CD40 [12]. CD23b mediates phagocytosis of soluble IgE complexes. An autocatalytic process involving cleavage of membrane bound CD23 by a matrix metalloprotease yields a series of soluble elements (sCD23) which increase IgE production via the $\mathrm{CD} 21$ receptor on $\mathrm{B}$ cells $[13,14]$.

The CD23 receptor has been shown to be upregulated on monocytes and alveolar macrophages in a T helper cell type 2 (TH2) environment and may contribute to chronic inflammation in asthma through this mechanism [15]. It has been shown that IL-4 and GM-CSF induce CD23 expression on monocytes, and GM-CSF primes monocytes for cellular activation and secretion of IL-1 upon subsequent exposure to IgE-containing immune complexes [8]. CD23 is also involved in antigen presentation to $\mathrm{B}$ cells as well as cellular interactions between $\mathrm{B}$ and $\mathrm{T}$ cells [12].

In previous studies, Hakonarson et al. [16] demonstrated the expression of CD23 (FceRII) messages and a low level of the protein in airway smooth muscle cells. In two patients who died of status asthmaticus, CD23 expression was also markedly upregulated on ASMC. The CD23 expression was inducible with human atopic sera or IgE immune complexes in naïve (control) ASMC, and this upregulation was blocked when pretreated with antiCD23 blocking antibody. The authors concluded that IgE coupled activation of CD23 contributes largely to its upregulation $[5,14]$. In a corresponding experiment with rabbit ASMC subjected to control and atopic serum, they were able to demonstrate, through Western blot analysis, a markedly enhanced expression of CD23 in the ASMC sensitized with atopic serum or IgE immune complexes. They were able to achieve significant inhibition of upregulation by pretreatment with anti-CD23 mAb. They hypothesized that IgE was responsible for the upregulation of the low affinity IgE receptor [17]. Hakonarson, et al. have also demonstrated that ASMC in vitro exposed to human atopic sera results in an initial increase in TH2 cytokines including IL-5 and GM-CSF followed hours later by production of IL-1 and TH1 cytokines $[18,19]$. Recently, phase I trials have been completed on IDEC152, an IgG1 anti-CD23 antibody, for patients with mild to moderate persistent asthma. The drug was well tolerated by participants, and a dose-dependent decrease in mean IgE values was reported [20].

T helper cell type 2 (TH2) mediated inflammatory cytokines, such as IL-4, IL-13, and IL-5, as well as other enzymes and chemokines are active in the asthmatic patient. GM-CSF has been shown to be involved in asthma pathogenesis and in vivo can induce TH2 differentiation independent of IL-4 [21]. Tryptase and prostagladin D2 (PGD2) were chosen as major mast cell mediators, and more recently the PGD2 receptor gene (PTGDR) has been shown to be an asthma susceptibility gene [22-24]. It is possible that many factors are responsible for the upregulation of the low affinity IgE receptor in addition to and independent of IgE. The purpose of this study was to identify specific mediators released in the asthmatic patient that are responsible for the upregulation of $\mathrm{CD} 23$ on human airway smooth muscle cells independent of IgE. 


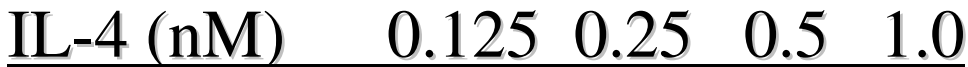

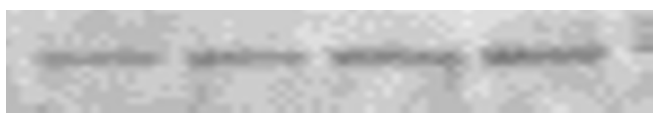

\section{GM-CSF (nM) $\quad 0.1 \quad 0.2 \quad 0.4 \quad 0.8$}

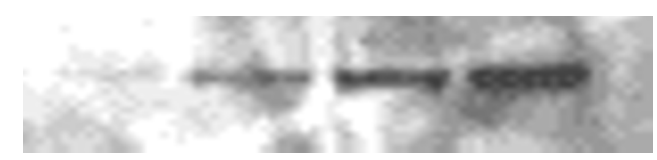

$\underline{24 h r}$

\section{$-\mathrm{CD} 23(45 \mathrm{kD})$}

\section{$-\mathrm{CD} 23(45 \mathrm{kD})$}

\section{Figure I}

Upregulation of CD23 by IL-4 and GM-CSF. Dose-ranging studies were performed to determine the optimum concentrations of IL-4 and GM-CSF. Alpha-smooth muscle isoactin positive Human ASMC (Clonetics) in T-75 flasks were starved for $24 \mathrm{~h}$ in $0.1 \% \mathrm{FBS}$ containing medium MI99. The cells were then stimulated with BSA (I $\mu \mathrm{g} / \mathrm{ml})$, IL-4 (0.125. 0.25, 0.5, or I.0 nM) or GM-CSF $(0.1,0.2,0.4$, or $0.8 \mathrm{nM})$ for $24 \mathrm{~h}$. The cell lysates in RIPA buffer were subjected to western blot analysis for CD23. Mouse anti-human CD23 monoclonal antibody (clone M-L233, BD Biosciences, I $\mu \mathrm{g} / 5 \mathrm{ml}$ ) was used as the primary antibody and anti-mouse horseradish peroxidase linked antibody as the secondary antibody (Amersham). The immunoreactive protein bands were detected by enhanced chemiluminescence light (ECL) (Amersham).

\section{Methods}

\section{Cell culture and flow cytometry}

Alpha-smooth muscle isoactin positive Human ASMC (Cambrex, Walkersville, MD) in T-75 flasks were starved for 24 hours in $0.1 \%$ (vol/vol) fetal bovine serum (FBS) containing medium M199 (Cellgro, Herndon, VA) supplemented with $1 \%$ (vol/vol) antibiotic/antimycotic solution (Sigma Chemical Co., St Louis, MO). The cells were then stimulated with either vehicle (bovine serum albumin, BSA, vehicle for cytokines ( $1 \mathrm{mg} / \mathrm{ml})$, in M199; ethanol (EtOH), vehicle for LTD4 (6\% final concentration) and PGD2 (0.001-0.01\% final concentration); M199, vehicle for tryptase), an individual mediator, or a mediator in combination with GM-CSF at their optimum concentrations for 24 hours. The doses of cytokines used were up to four time ED50 including: IL-4 (0.04-1 nM), GMCSF (0.07-0.8 nM), IL-13 (0.4 nM), IL-5 (0.01-0.07 nM), IL-13 $(0.3-2.2 \mathrm{nM})$, PGD2 $(1-10 \mu \mathrm{M})$, LTD4 $(1-10 \mu \mathrm{M})$, tryptase (30 nM, a concentration sufficient to induce ASMC proliferation) (Sigma). Dose ranging studies were performed to determine the optimum concentration of IL-4 and GM-CSF on the expression of CD23, and the doses chosen were IL-4 (0.5 nM) and GM-CSF (0.4 nM) (Figure 1). All cytokines were obtained from R \& D Systems Inc. Minneapolis, MN except GM-CSF which was obtained from Sigma. The cells were then harvested with a soft rubber edged scraper, centrifuged for 5 minutes at $1000 \mathrm{rpm}(200 \mathrm{~g})$, washed and resuspended in 1\% BSA in phosphate buffered saline (PBS) and fixed with $70 \%$ ETOH. After washing twice more, the cells were resuspended in 1\% BSA in PBS. Finally, they were filtered through a $40 \mu \mathrm{m}$ nylon mesh to obtain single cell suspension and stained with $(20 \mu \mathrm{l})$ of PE (phycoerythrin)-CD23 (EBVCS-5, BD Biosciences, San Jose, CA) or PE-mouse $\mathrm{IgG}_{1}$ for 15 minutes in the dark to facilitate staining for flow cytometry. 


\section{Protein analysis}

A commercially available bicinchoninic acid (BCA) kit (Pierce, Rockford, IL) was used for protein analysis according to the manufacturer's instructions. The optical densities were read using a Bio-Kinetics EL-312 Microplate reader.

\section{Indirect immunofluorescence}

Indirect immunofluorescence stainings were performed with anti-smooth muscle- $\alpha$ isoactin antibody (Sigma) and anti-human CD23 antibody (M-L233, $1 \mu \mathrm{g} / \mathrm{ml}$, BD Biosciences), which are specific monoclonal antibodies and either a FITC or TRITC fluorochrome, conjugated second antibody. Fixed huASMC were incubated with the above antibodies diluted in PBS with 3\% BSA for $60 \mathrm{~min}$ at room temperature. The cells were then washed three times with PBS for 10 minutes for each wash. Non-specific binding was blocked by incubating cells with 3\% BSA in PBS for 60 minutes. The blocking solution was then removed and cells were incubated with FITC- or TRITCfluorochrome conjugated antibody for 45 minutes in the dark to facilitate staining. Cells were then washed with PBS three times. Finally, one drop of Fluoromount-G (Southern Biotechnology Inc., Birmingham, AL) was added.

\section{Western blot}

Standard Western blot analyses were performed to detect anti-STAT6 (1:500, Calbiochem, San Diego, CA) polyclonal rabbit, anti-p-STAT-6 (1:500, Calbiochem) polyclonal rabbit. Human ASMC lysates in radio-immunoprecipitation assay (RIPA) buffer were transferred onto HybondECL nitrocellulose membranes and were immunoblotted with monoclonal anti-human CD23 (1:500 dilution, clone M-L233, $1 \mu \mathrm{g} / 5 \mathrm{ml}$, BD Biosciences), polyclonal anti-IL-4R $\alpha$ (1:500 dilution, Santa Cruz), monoclonal anti-IL-2R $\gamma$ c (1:250 dilution, R\&D Systems, Inc.). The nitrocellulose membranes were incubated with a 1:1,000 dilution of anti-rabbit or anti-mouse horseradish peroxidase linked whole antibody (Amersham, Piscataway, NJ) in PBS-T for 1 hour at room temperature. Paxillin monoclonal antibody (1:500 dilution, Transduction Laboratories) was used as a positive isotype control for CD23, and fibronectin polyclonal antibody (1:250, Sigma) was used as a positive control for the remaining antibodies. The immunoreactive protein bands were detected by enhanced chemiluminescence light (ECL) (Amersham).

\section{Statistical analysis}

Data were analyzed with Prism 4 software (GraphPad, San Diego, CA). One-way analysis of variance (ANOVA) was used. Results are expressed as mean \pm SEM. A P value less than 0.05 was considered statistically significant.

\section{Results \\ CD23 protein expression is upregulated in huASMC by IL- 4, GM-CSF, or IL-4/GM-CSF}

Previous studies have shown that IgE immune complexes in atopic serum caused an increase in CD23 expression in ASMC [16]. To determine if other humoral factors in atopic serum effect CD23 expression in human ASMC, we have tested the effect of the relevant cytokines, arachidonic acid metabolites, and the mast cell enzyme tryptase. Flow cytometry was performed to evaluate differences in cell populations after stimulation of the huASMC for 24 hours with either individual mediators IL-4 (0.5 nM), GM-CSF (0.4 nM), IL-13 (0.4 nM), IL-5 (0.4 nM), PGD2 $(10 \mu \mathrm{M})$, LTD $4(10 \mu \mathrm{M})$, tryptase $(30 \mathrm{nM})$ or a combination of IL-4, IL-5, and IL-13 each with GM-CSF. Within the huASMC stimulated by IL-4, GM-CSF or the combination of IL-4/GM-CSF, two populations of cells were detected distinguishable by cell size. While the smaller cells did not show a significant expression of CD23, many of the larger cells showed increased expression of CD23. In the example in Figure 2, 66\% of the larger cells (gate D) showed an increase in cell expression of CD23 when compared to the controls. As stated previously, the functions of ASMC are heterogeneous including proliferation and synthesis. Previous studies have shown, on flow cytometry of ASMC stimulated in vitro with IL- $1 \beta$ and TNF- $\alpha$, only $20-60 \%$ of ASMC produce GM-CSF. The ASMC producing GM-CSF include some which also have increased proliferative properties. This suggests that considerable heterogeneity exists in the phenotypic expression of the ASMC in culture [25].

In addition to the combination of IL-4/GM-CSF inducing increased expression of CD23, both IL-4 and GM-CSF alone independently increased the expression of CD23 in huASMC. The percentage of cells with increased fluorescence intensity above the control was $25.1 \pm 4.2 \%$ (IL-4), $15.6 \pm 2.7 \%(\mathrm{GM}-\mathrm{CSF})$ and $32.9 \pm 13.9 \%$ (IL-4/GM-CSF combination). On the other hand, IL-5, IL-13, cysteinyl leukotrienes, and tryptase did not induce CD23 expression (Table 1).

\section{Expression of CD23 in response to IL-4, GM-CSF, IL-4/GM- CSF is accompanied by changes in huASMC morphology}

Western blot analysis of huASMC stimulated with IL-4, GM-CSF, or Il-4/GM-CSF for $24 \mathrm{~h}$ showed an increase in CD23 expression compared to BSA vehicle control (Figure 3). Indirect immunofluorescence was used also to identify any morphological changes associated with the cytokine stimulation and upregulation of CD23 (Figure 4A-D). Those cells stimulated with the combination of IL-4/GMCSF demonstrated CD23 expression along with changes in cell morphology including depolymerization of isoactin fibers, cell spreading, and membrane ruffling (Figure $4 \mathrm{~B})$. These changes in phenotype are consistent with flow 


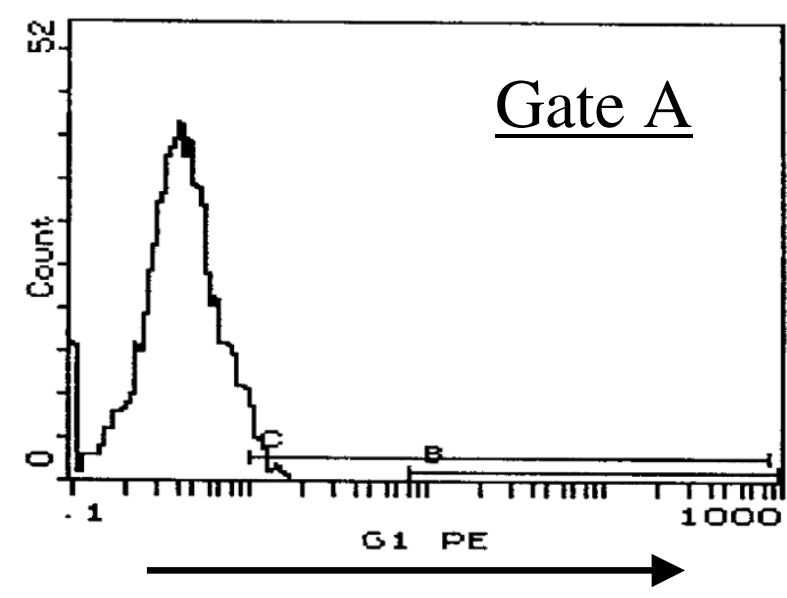

\section{Fluorescence Intensity}

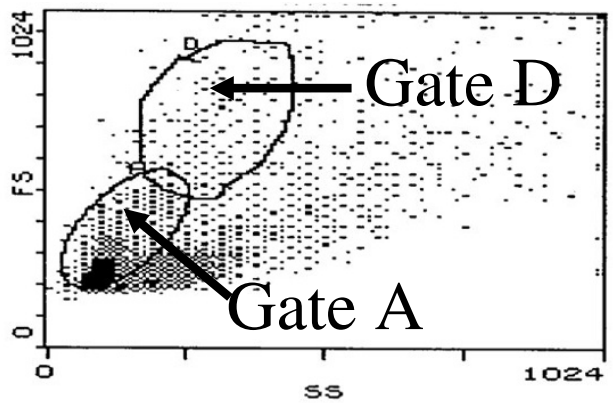

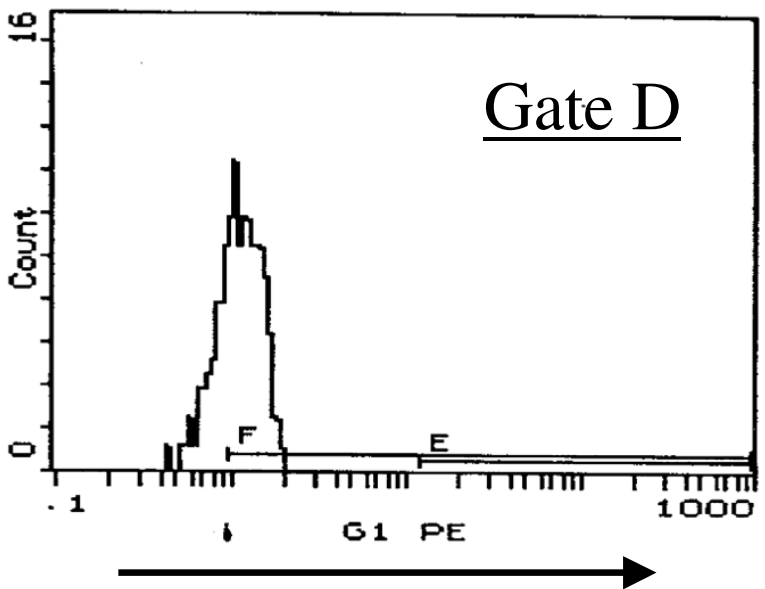

Fluorescence Intensity

Figure 2

Upregulation of CD23 by IL-4, GM-CSF and IL-4/GM-CSF. Alpha-smooth muscle isoactin positive Human ASMC (Clonetics) in T-75 flasks were starved for $24 \mathrm{~h}$ in $0.1 \%$ FBS containing medium MI99. The cells were then stimulated with IL$4(0.5 \mathrm{nM}) / \mathrm{GM}-\mathrm{CSF}(0.4 \mathrm{nM})$ for $24 \mathrm{~h}$. The FACS analysis showed that the smaller cells passed through Gate A and larger cells passed through Gate D. Background noise was eliminated using the BSA-stimulated control cells that were labeled with PEanti-CD23 (EBVCS), represented by C in Gate A, and F in Gate D. The FACS results of a representative experiment showed $66 \%$ of the larger cells (Gate D) had an increase in cell expression of CD23 when compared to the controls.

cytometry results in that the larger cells expressed CD23 (Figure 4D). In contrast, the control BSA stimulated population showed no changes in cell cytoskeletal structure and morphology (Figure 4A) or specific staining for CD23 (Figure 4C).

To confirm activity of protein synthesis, the protein content of the control and the experimental groups of cells were compared using a BCA protein analysis kit. Human ASMC were starved for 24 hours in $0.1 \%$ FBS containing medium M199 and then stimulated with BSA $(1 \mu \mathrm{g} / \mathrm{mL})$, IL-4 (0.5 nM), GM-CSF (0.4 nM), or IL-4 (0.5 nM)/GMCSF $(0.4 \mathrm{nM})$ for 24 hours. The protein content was increased by $19 \%$ in the IL-4/GM-CSF treated cells above that of the control (Table 2). The increase in protein concentration with IL-4 alone was not statistically significant.

\section{Stimulation of huASMC with IL-4 induces phosphorylation of STAT-6 and expression of IL-2R $\gamma \mathrm{C}$}

IL-4 binds the IL-4R with high affinity, and signaling through IL-4 causes enhanced expression of IL-4R [21]. The induction of these genes is mediated through signal transduction molecules including signal transducer activator of transcription (STAT-6). The binding of IL-4 to its receptor complex induces the formation of an IL-4 receptor complex which consists of IL- $4 \mathrm{R} \alpha$ and the common gamma chain $(\gamma c)$ of the receptors for IL-2, IL-4, IL-7, IL9, IL-15, and IL-21 [21]. It has not been previously 
Table I: II-4, GM-CSF, and IL-4/GM-CSF Increase CD23 Expression on ASMC ( $=3)$

\begin{tabular}{lcc}
\hline \multicolumn{1}{c}{ Cytokine (24 hours) } & $\begin{array}{c}\text { \#Cells in Gate D } \\
(\mathrm{n}=3)\end{array}$ & $\begin{array}{c}\text { \%Cells with Increased CD23 } \\
\text { Expression Above the Control }\end{array}$ \\
\hline BSA $(I \mu \mathrm{g} / \mathrm{ml})$ & $1,343 \pm 122$ & 0 \\
IL-4 $(0.5 \mathrm{nM})$ & $1,413 \pm 197$ & $25.1 \pm 4.2^{*}$ \\
GM-CSF $(0.4 \mathrm{nM})$ & $1,346 \pm 243$ & $15.6 \pm 2.7^{*}$ \\
IL-4/GM-CSF $(0.4 / 0.5 \mathrm{nM})$ & 1,324203 & $32.9 \pm 13.9 *$ \\
IL-5 $(0.4 \mathrm{nM})$ & $1,130 \pm 251$ & 0 \\
IL-I3 $(0.4 \mathrm{nM})$ & $1,316 \pm 269$ & 0 \\
PGD2 $(I \mu M)$ & $1,521 \pm 123$ & 0 \\
PGD2 $(I 0 \mu \mathrm{M})$ & $1,159 \pm 204$ & 0 \\
LTD4 $(10 \mu \mathrm{M})$ & $2,037 \pm 375$ & 0 \\
Ethanol $(6 \% \mathrm{vol} / \mathrm{vol})$ & $2,507 \pm 200$ & 0 \\
Tryptase $(10 \mu \mathrm{M})$ & $2,385 \mathrm{ne} \pm 405$ & 0 \\
\hline
\end{tabular}

Alpha-smooth muscle isoactin positive Human ASMC (Clonetics) in T-75 flasks were starved for $24 \mathrm{~h}$ in $0.1 \%$ FBS containing medium MI 99 . The cells were then stimulated with BSA ( $1 \mu \mathrm{g} / \mathrm{ml})$, IL-4 (0.5 nM), GM-CSF $(0.4 \mathrm{nM})$, IL-4 (0.5 nM)/GM-CSF (0.4 nM), IL- 13 (0.4 nM), IL-5 (0.4 nM), PGD2 $(10 \mu \mathrm{M})$, LTD4 $(10 \mu \mathrm{M})$, tryptase $(30 \mathrm{nM})$ for $24 \mathrm{~h}$. Results are mean \pm SEM of the percentage of cells with an increased fluorescence intensity above the control $(n=3)$. Control values: BSA-stimulated, PE-anti-CD23 labeled, $10.9 \pm 1.4 \%$; BSA-stimulated, PE-mouse IgG , nonimmune, $0.5 \pm 0.1 \%(n=3)$. *denotes significant increase in CD23 expression above the BSA control value.

\begin{tabular}{|c|c|c|c|c|c|}
\hline & \multirow{2}{*}{$\frac{\mathrm{BSA}}{(1 \mu \mathrm{g} / \mathrm{ml})}$} & \multirow{2}{*}{$\frac{\text { IL-4 }}{(0.5)}$} & \multicolumn{3}{|c|}{ GM-CSF IL-4/GM-CSF } \\
\hline & & & $(0.4)$ & $(0.5 / 0 / 4)$ & $\mathrm{nM}(24 \mathrm{~h})$ \\
\hline $45 \mathrm{kD}-$ & $=$ & - & $=$ & $\Longrightarrow$ & $-\mathrm{CD} 23$ \\
\hline $68 \mathrm{kD}$ & & & & & -paxillin \\
\hline
\end{tabular}

\section{Figure 3}

Western blot analysis of CD23 after stimulation of IL-4, GM-CSF, IL-4/GM-CSF. Alpha-smooth muscle isoactin positive huASMC (Clonetics) in T-75 flasks were starved for $24 \mathrm{~h}$ in $0.1 \% \mathrm{FBS}$ containing medium MI99. The cells were then stimulated with BSA (I $\mu \mathrm{g} / \mathrm{ml}$ ) (vehicle control), IL-4 $(0.5 \mathrm{nM})$, GM-CSF $(0.4 \mathrm{nM})$, or IL-4/GM-CSF $(0.5 \mathrm{nM} / 0.4 \mathrm{nM})$ for $24 \mathrm{~h}$. The cell lysates in RIPA buffer were subjected to western blot analysis for CD23. Mouse anti-human CD23 monoclonal antibody (clone M-L233, BD Biosciences, I $\mu \mathrm{g} / 5 \mathrm{ml}$ ) was used as the primary antibody and anti-mouse horseradish peroxidase linked antibody as the secondary antibody (Amersham). The immunoreactive protein bands were detected by enhanced chemiluminescence light $(\mathrm{ECL})$ (Amersham). Paxillin mouse monoclonal $\lg \mathrm{G}_{\mathrm{I}}$ (Transduction Laboratories) was used as an irrelevant isotype control. 


\section{$\alpha$-isoactin}

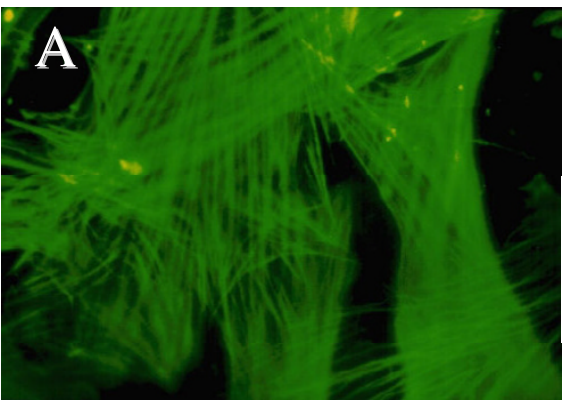

\section{BSA}

\section{GM-CSF}

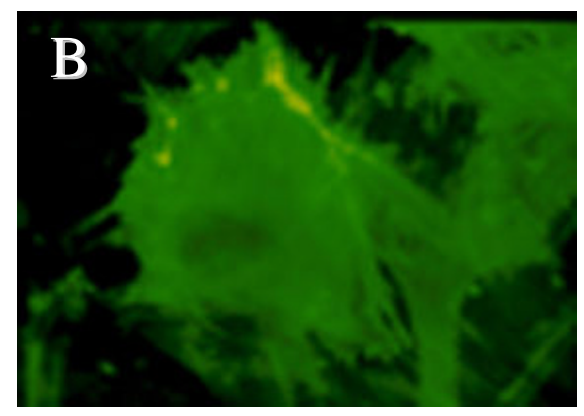

$\alpha-$ isoactin
$\mathrm{CD} 23$

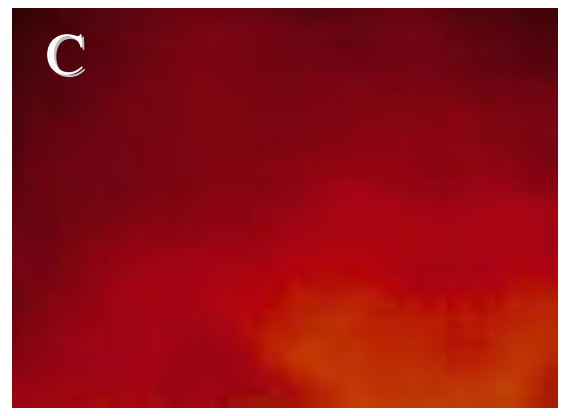

\section{BSA}

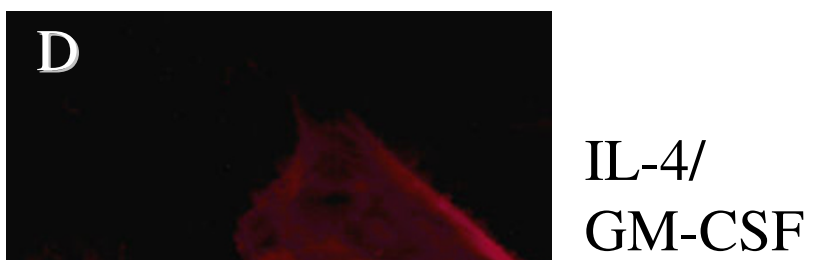

\section{Figure 4}

Expression of CD23 in response to IL-4/GM-CSF is accompanied by changes in huASMC morphology. Alphasmooth muscle isoactin positive huASMC (Clonetics) in T-75 flasks were starved for $24 \mathrm{~h}$ in $0.1 \% \mathrm{FBS}$ containing medium MI99. The cells were then stimulated with either BSA or IL-4 $(0.5 \mathrm{nM}) / \mathrm{GM}-\mathrm{CSF}(0.4 \mathrm{nM})$ for $24 \mathrm{~h}$, and stained with either antismooth muscle-isoactin (A \& B) or anti-CD23 antibody (C \& D). Those cells stimulated with the combination of IL-4/GM-CSF demonstrated CD23 expression (D) and changes in cell morphology including depolymerization of isoactin fibers, cell spreading, and membrane ruffling (B). Cells stimulated with BSA (vehicle for IL-4/GM-CSF) alone did not increase the expression of CD23 (C) nor changes in phenotype (A). These findings were confirmed by three independent observers.

Table 2: IL-4/GM-CSF Combination Increases Protein Content in huASMC.

\begin{tabular}{lc}
\hline \multicolumn{1}{c}{ Cytokine $(\mathrm{nM})$} & $\mathrm{mg} / \mathrm{I} 0^{6}$ cells $(\mathrm{n}=3)$ \\
\hline BSA (vehicle) & $1.17 \pm 0.08$ \\
IL-4 (0.5) & $1.18 \pm 0.01$ \\
GM-CSF & $1.12 \pm 0.03$ \\
IL-4 $(0.5) / G M-C S F ~(0.4)$ & $1.39 \pm 0.02 *$ \\
\hline
\end{tabular}

Alpha-smooth muscle isoactin positive huASMC (Clonetics) in T-75 flasks were starved for $24 \mathrm{~h}$ in $0.1 \%$ FBS containing medium MI 99. The cells were then stimulated with BSA $(\mathrm{I} \mu \mathrm{g} / \mathrm{ml}))$, IL-4 $(0.5 \mathrm{nM})$, GM-CSF (0.4 nM), or IL-4/GM-CSF $(0.4 / 0.5 \mathrm{nM})$ for $24 \mathrm{~h}$. The cell lysates in RIPA buffer were analyzed for protein content using a commercially available BCA kit (Pierce). The optical density was read using a Bio-Kinetics EL-3 I 2 Microplate reader. Results are mean \pm SEM $(n=3)$. *denotes value significantly different from the BSA vehicle treated control. reported that airway smooth muscle cells express the IL$2 \mathrm{R} \gamma \mathrm{c}$, the signaling unit of the IL-4 receptors.

Western blot analysis of IL- $4 \mathrm{R} \alpha$ and IL-2R $\gamma \mathrm{c}$ in huASMC lysates showed the presence of these receptor components on huASMC. Figure 5 shows abundant expression of IL$4 \mathrm{R} \alpha$ and a low level expression of IL-2R $\gamma \mathrm{c}$ protein on huASMC. After stimulation of huASMC with IL-4 (0.4 $\mathrm{nM}$ ) for $24 \mathrm{~h}$, a two fold increase in $\gamma_{\mathrm{c}}$ expression was observed compared to the BSA vehicle control (Figure 6).

To confirm that IL- 4 was activating the IL-4R $\alpha$ during the stimulation of huASMC, we examined the phosphorylation of downstream STAT-6 by western blot. Human ASMC were starved for $24 \mathrm{~h}$ and then stimulated with IL$4(0.4 \mathrm{nM})$ for fifteen minutes. Results of Western blot revealed an approximately a four fold increase in intensity 


\section{$1 \quad$ M.W.

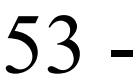 \\ IB: anti-IL-4R $\alpha$

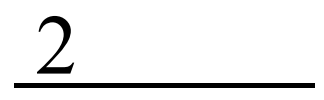 \\ IL-4R $\alpha-$

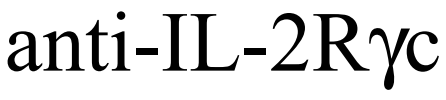

\section{Figure 5}

IL-4R $\alpha$ and IL-2R $\gamma$ c Expression in huASMC. A: IL-4R $\alpha$ and IL-2R $\gamma c$ expression in huASMC at baseline. Unstarved huASMC lysates were subjected to western blot analysis for IL-4R $\alpha$ and IL-2R $\gamma$ c using polyclonal anti-IL-4R $\alpha$ (I:500 dilution, Santa Cruz), or monoclonal anti-IL-2R $\gamma \mathrm{c}$ (I:I25 dilution, R\&D Systems, Inc.). The nitrocellulose membranes were incubated with a I:I,000 dilution of anti-rabbit or anti-mouse horseradish peroxidase linked whole antibody (Amersham). The immunoreactive protein bands were detected by ECL (Amersham). IL-2R $\gamma c$ is minimally expressed in huASMC while IL-4R $\alpha$ is expressed abundantly in huASMC.

of the band for phosphorylated-STAT-6 in IL-4 stimulated cells when compared to BSA control (Figure 7). This supports the role of an IL-4 mediated signal transduction pathway involvement in CD23 upregulation in huASMC.

\section{Discussion}

In our study, we have demonstrated that CD23, the low affinity IgE receptor, is upregulated on human airway smooth muscle cells by the cytokines IL-4, GM-CSF, and the combination of IL-4/GM-CSF. This upregulation of CD23 by the combination of IL-4 and GM-CSF was accompanied by an increase in cell volume and protein content, cytoskeletal depolymerization, cell spreading and membrane ruffling. Because ASMC require a doubling time of 48 hours, the increase in protein content could not be attributed to an increase in cell number. Also, the increase in cell number in gate D seen with LTD4 was likely secondary to the effects of ethanol (Table 1). Stimulation of huASMC by IL-4 caused an activation of STAT- 6 and an increase in $\gamma c$ expression. Collectively, our findings suggest that CD23 expression can be stimulated by IL- 4 and GM-CSF cytokines independent of IgE in huASMC and the upregulation of CD23 may play a role in cell migration and hypertrophy.

Previous studies have demonstrated an increase in CD23 expression in alveolar monocytes after stimulation with IL-4 and GM-CSF [10]. In that study, the use of the individual mediators alone did not increase the CD23 levels to that of asthmatic patients suggesting a possible synergistic role between IL- 4 and GM-CSF. Our findings are consistent with these in that the combination of IL-4 and GM-CSF was most effective in upregulating CD23 in huASMC. Not all TH2 cytokines are involved in this process; IL-5 (0.4 nM) and IL-13 (0.4 nM) had no effect on CD23 expression. Cysteinyl leukotriene LTD4 (10 $\mu \mathrm{M})$, prostaglandin PGD2 $(10 \mu \mathrm{M})$ and tryptase (30 $\mathrm{nM})$ did not induce CD23 expression on huASMC [26]. 


\section{M.W. BSA IL-4 GM-CSF IL-4/GM-CSF $\mathrm{kD} \quad(1 \mu \mathrm{g} / \mathrm{ml})(0.5 \mathrm{nM})(0.4 \mathrm{nM}) \quad(0.5 / 0.4 \mathrm{nM})$}

$140-$

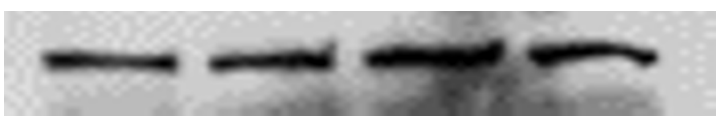

$53-$

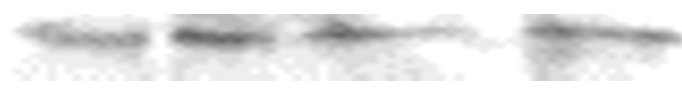

$220-$

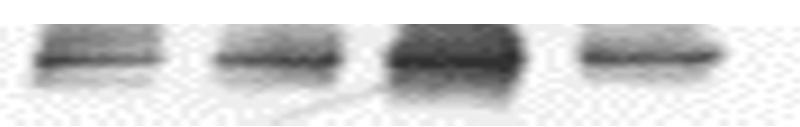

$-\mathrm{IL}-4 \mathrm{R} \alpha$

$-\mathrm{IL}-2 \mathrm{R} \gamma \mathrm{c}$

\section{-fibronectin}

\section{Figure 6}

Upregulation of IL-2R $\gamma$ c Expression in huASMC by IL-4 and IL-4/GM-CSF. Alpha-smooth muscle isoactin positive Human ASMC (Clonetics) in T-75 flasks were starved for $24 \mathrm{~h}$ in $0.1 \%$ FBS containing medium MI 99. The cells were then either stimulated with BSA (vehicle) $(\mathrm{I} \mu \mathrm{g} / \mathrm{ml})$, IL-4 $(0.5 \mathrm{nM})$, GM-CSF $(0.4 \mathrm{nM})$, or IL-4/GM-CSF $(0.5 \mathrm{nM} / 0.4 \mathrm{nM})$ for 24 hours. The IL-4 and IL-4/GM-CSF stimulated cells had increased IL-2R $\gamma c$ expression compared to the BSA (vehicle) group. Fibronectin polyclonal rabbit antibody (Sigma) (I:250) was used as an irrelevant isotype control.

We evaluated the effect of stimulation of huASMC with IL4 on phosphorylation of STAT- 6 via the IL-4R which would confirm the presence of the receptor in huASMC. STAT- 6 is a critical mediator of IL- 4 stimulated gene activation, and it is regulated by both tyrosine and serine kinases [27]. It has been shown in a mouse model that STAT-6 binds the CD23a murine promoter, and STAT -/mice stimulated with IL- 4 are unable to upregulate CD23.
This suggests STAT-6 is a critical mediator for IL- 4 induced upregulation of CD23 [28]. IL-4 along with CD40 mediated signals are responsible for upregulation of CD23 on $\mathrm{B}$ cells [14]. In this study, we have confirmed the expression of the IL-4R $\alpha$ and a low level of common gamma chain in huASMC and that after stimulation of huASMC with IL-4, there was a two fold increase in $\gamma c$ chain expression (Figure 6). Phosphorylation of STAT-6 


$\begin{array}{ccccc}\text { MW } & \text { BSA } & \text { IL-4 } & \text { GM-CSF } & \text { IL-4/GM-CSF } \\ (\mathrm{kD}) & (1 \mu \mathrm{g} / \mathrm{ml}) & (0.5 \mathrm{nM}) & (0.4 \mathrm{nM}) & (0.5 / 0.4 \mathrm{nM}) \\ & & & 15 \text { min Incubation }\end{array}$
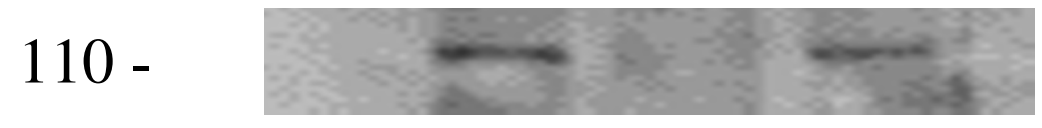

$110-$
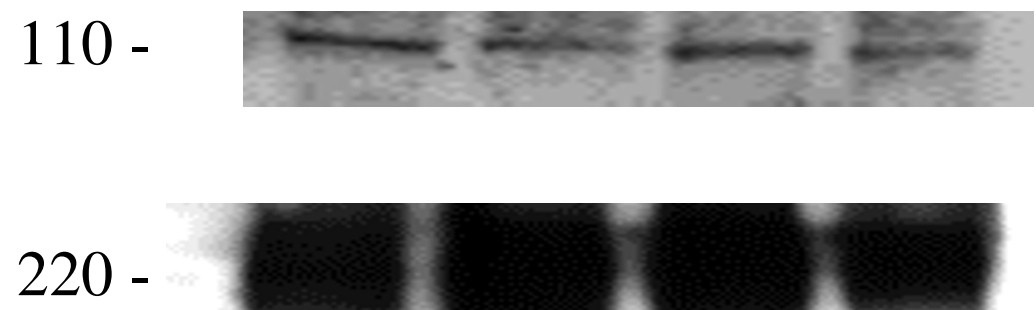

-p-stat 6

-stat-6

-fibronectin

\section{Figure 7}

Phosphorylation of STAT-6 by IL-4 and IL-4/GM-CSF in huASMC. Starved huASMC were incubated with either BSA vehicle control (I $\mu \mathrm{g} / \mathrm{ml})$, IL-4 (0.5 nM), GM-CSF (0.4 nM), or IL-4/GM-CSF (0.5 nM/0.4 nM) for I 5 minutes. Standard Western blot analyses were performed to detect STAT-6 and phosphorylated-STAT-6 (P-STAT-6) using a anti-STAT-6 polyclonal rabbit antibody (Calbiochem) and anti-p-STAT-6 polyclonal rabbit antibody (Calbiochem). Anti-rabbit horseradish peroxidase linked antibody was used as the secondary antibody. Protein bands were detected by ECL. STAT- 6 was abundantly expressed by all four groups, while P-STAT-6 was only expressed in the IL-4 and IL-4/GM-CSF groups. Fibronectin polyclonal rabbit antibody (Sigma) was used as an irrelevant isotype control and was abundantly expressed in all four groups.

after stimulation with IL-4 for 15 min confirms that IL-4 has bound and activated the IL- 4 receptor complex (Figure 7). It has been shown that the common gamma chain is a functional $\beta$ chain of the IL- 4 receptor complex in certain cells [27], and our data suggest that this is the case in huASMC. Interestingly, IL-13 (4 nM, a concentration sufficient to simulate huASMC proliferation, unpublished observation) did not upregulate CD23. For proliferation of ASMC by IL-13, IL-4R $\alpha$ and IL-13R $\alpha 1$ are required for signal transduction and downstream activation of p44/42 extracellular regulated kinases (ERK, unpublished data). Apparently, IL-4R $\alpha$ and IL-13R $\alpha 1$ engagement is not suf- ficient for CD23 expression, further supporting the role of $\gamma c$ chain in CD23 expression by IL-4. The signs of signal transduction in response to IL-4, and the increase in protein content of the cell in response to IL-4 and GM-CSF combination (Table 2) represent activation of transcription and translation of CD23 in this case. Coupling of GM-CSF and its receptor complex is known to activate ERK that may have contributed to the synergistic effect of GM-CSF on CD23 expression.

CD23 expression was associated with changes in cell morphology including depolymerization of isoactin fibers, 
cell spreading, and membrane ruffling (Figure 4B \&4D). Actin in ASMC is in a dynamic state and undergoes polymerization-depolymerization during the contractionrelaxation cycle $[29,30]$. Membrane ruffling and cell migration involve signaling pathways including PI3kinase, Rac and other Rho family $\mathrm{G}$ protein members in a variety of cell types, including vascular smooth muscle cells. Rac has an essential role in cell migration and regulation of the actin cytoskeleton [31,32]. Moreover, ASMC are capable of switching their phenotypes from contractile to synthetic phenotype that is mediated by Rho kinases $[32,33]$.

In summary, we have demonstrated that the low affinity IgE receptor can be induced on huASMC by specific cytokines including IL-4, GM-CSF, and the combination of IL-4/GM-CSF. The combination of IL-4/GM-CSF also induced morphologic changes in the ASMC that may contribute to the synthetic function or migration. In addition, IL-4 and IL-4/GM-CSF stimulation of huASMC increased the protein content of the cell, suggesting hypertrophy.

\section{Conclusion}

T helper type 2 cytokines including IL-4 have major role in asthma pathogenesis. GM-CSF is a hemopoetic growth factor, mostly released by activated monocytes and T cells. Additional sources of GM-CSF include epithelium of asthmatic airways [34] and human airway smooth muscle cells $[6,35]$. Therefore, the effect of GM-CSF on CD23 expression can be both via paracrine and autocrine mechanisms. Previous studies by Hakonarson et al. [16,17] have shown that upregulation of the CD23 receptor has been associated with proasthmatic changes in agonistmediated ASM constrictor and relaxant responsiveness. Our study suggests that CD23 expression is associated with elements of hypertrophy (i.e. an increase in cell volume and protein content), thus consistent with their findings. Inhaled corticosteroids, the mainstay in treatment of asthma, effectively reduce inflammation and remodeling of the epithelium and basement membrane. However, no agents have been proven effective in reducing smooth muscle mass in asthmatic patients. Recent study results on anti-CD23 therapy showed decrease in serum IgE. Further studies to intervene the upregulation of CD23 expression by cytokines IL-4 and GM-CSF may open a new avenue to target smooth muscle hypertrophy, an important element of severe asthma [2].

\section{Competing interests}

The author(s) declare that they have no competative intrests.

\section{List of abbreviations}

huASMC: Human airway smooth muscle cells
FceRI: High-affinity receptor for IgE

FceRII (CD23): Low-affinity receptor for IgE

AHR: Airway hyperreactivity

PGD2: Prostaglandin D2

LTD4: Leukotriene D4

PE: Phycoerythrin

FBS: Fetal bovine serum

BSA: Bovine serum albumin

PBS: Phosphate bufferred saline

BCA: Bicinchoninic acid

FITC: Fluorescein Isothiocyanate

TRITC: Tetramethyl Rhodamine Iso-Thiocyanate

RIPA: Radio-immunoprecipitation assay

ECL: Enhanced chemiluminescence light

Ro: Receptor alpha

$\gamma c$ : Common gamma chain

FACS: Fluorescent Activated Cell Sorter

STAT: Signal Transducer Activator of Transcription

TH2: T helper cell type 2

ERK: Extracellular regulated kinases

\section{Authors' contributions}

JTB participated in designing experiments and performing CD23 analysis by flow cytometry.

RKG carried out flow cytometry, immunofluorescence studies, and drafted the manuscript.

HM carried out western blot analyses.

DBL supervised all aspects of the project.

All authors have read and approved the final manuscript.

\section{Acknowledgements}

This work was supported in part by the grant from the Le Bonheur Children's Medical Center, NIH-HL568I2, Children's Foundation Research 
Center, Molecular Resource Center, and American Academy of Allergy, Asthma and Immunology. The authors would like thank Jan Aldrich for her technical assistance.

\section{References}

I. Vignola AM: Effects of inhaled corticosteroids, leukotriene receptor antagonists, or both, plus long-acting beta2-agonists on asthma pathophysiology: a review of evidence. Drugs 2003, 63:35-5I.

2. Benayoun L, Druihe A, Dombret M-C, Aubier M, Pretolani M: Air way structural alterations selectively associated with severe asthma. Am J Respir Crit Care Med 2003, I 67:1360-8.

3. Woodruff PG, Dolganov GM, Ferrando RE, Donnelly S, Hays SR, Solberg OD, Carter R, Wong HH, Cadbury PS, Fahy JV: Hyperplasia of smooth muscle in mild to moderate asthma without changes in cell size or gene expression. Am J Respir Crit Care Med 2004, 169:1001-6.

4. Hirst SJ: Regulation of airway smooth muscle cell immunomodulatory function: role in asthma. Respir Physiol Neurobio 2003, I 37:309-26

5. Busse W, Banks-Schlegel S, Wenzel S: Pathophysiology of severe asthma, Nihlbi workshop summary. J Allerg Clin Immunol 2000 106: 1033-42.

6. Hakonarson H, Grunstein M: Autocrine regulation of airway smooth muscle responsiveness. Respir Physiol \& Neurobiol 2003, 137:263-76.

7. Madison M: Migration of airway smooth muscle cells:. Am Respir Cell Mol Biol 2003, 29:8-II.

8. Schmidt D, Rabe K: Immune mechanisms of smooth muscle hyperreactivity in asthma. J Allerg Clin Immunol 2000, I 05:673-83.

9. Broide D: Novel therapies in allergic disease: molecular and cellular mechanisms of allergic disease. J Allerg Clin Immunol 200I, I 08(SuppI):65-7I.

10. Matz J, Williams J, Rosenwasser L, Borish L: Granulocyte-macrophage colony-stimulating factor stimulates macrophages to respond to IgE via the low affinity IgE receptor (CD23). Allerg Clin Immunol 1994, 93:650-7.

II. Visan I, Goller M, Berberich I, Kneitz C, Tony HP: Pax-5 is a key regulator of the $B$ cell restricted expression of the CD23a isoform. Eur I Immunol 2003, 33: I I63-II73.

12. Novak N, Kraft S, Bieber T: IgE receptors. Curr Opinion in Immunol 200I, I 3:721-6.

13. Ewart MA, Ozanne BW, Cushley W: The CD23a and CD23b proximal promoters display different sensitivities to exogenous stimuli in B lymphocytes. Genes Immunol 2003, 3: I58-64.

14. Oettgen $H$, Geha $\mathrm{R}$ : IgE regulation and roles in asthma pathogenesis. J Allerg Clin Immunol 200I, 107:429-40

15. Harkins MS, Moseley PL, Iwamoto GK: Regulation of CD23 in the chronic inflammatory response in asthma: a role for inter feron-gamma and heat shock protein 70 in the TH2 environment. Ann Allergy Asthma Immunol 2003, 6:567-74.

16. Hakonarson H, Carter C, Kim C, Grunstein M: Altered expression and action of the low-affinity IgE receptor FCRII (CD23) in asthmatic airway smooth muscle. I Allerg Clin Immunol 1999 , I 04:575-84

17. Hakonarson H, Grunstein MM: Autologously up-regulated Fc receptor expression and action in airway smooth muscle mediates its altered responsiveness in the atopic asthmatic sensitized state. Proc Nat Acad Sci 1998, 95:5257-62

18. Hakonarson H, Maskeri N, Carter C, Grunstein M: Regulation of THI - and TH2-tye cytokine expression and action in atopic asthmatic sensitized airway smooth muscle. J Clin Invest 1999, 103:1077-87.

19. Hakonarson H, Maskeri N, Kim C, Grunstein M: Autocrine interaction between IL-5 and IL-I mediates altered responsiveness of atopic asthmatic sensitized airway smooth muscle. J Clin Invest 1999, I 04:657-67.

20. Rosenwasser L, Busse W, Lizambri R, Olejnik T, Totoritis : Allergic asthma and anti-CD23 mAb (IDEC-I 52): Results of a phase I, single-dose, dose-escalating clinical trial. J Allerg Clin Immuno 2003, I | 2:563-70.

21. Ritz SA, Cundall M, Gajewska B, Alvarez D, Gutierrez-Ramos J, Coyle A, McKenzie A, Stampfli M, Jordana M: Granulocyte macrophage colony-stimulating factor-driven respiratory mucosal sensiti- zation induces Th2 differentiation and function independently of interleukin-4. Am J Respir Cell Mol Biol 2002, 27:428-435

22. Schwartz LB, Bradford TR: Regulation of tryptase from human lung mast cells by heparin. Stabilization of the active tetramer. J Biol Chem 26 I( I 6):7372-9. 1986 Jun 5

23. Brightling CE, Bradding P, Symon FA, Holgate ST, Wardlaw AJ, Pavord ID: Mast-cell infiltration of airway smooth muscle in asthma: N Engl J Med 346(22): I699-705. 2002 May 30

24. Oguma T, Palmer LJ, Birben E, Sonna LA, Asano K, Lilly CM: Role of prostanoid DP receptor variants in susceptibility to asthma: N Engl J Med 35 I ( I 7): I752-63. 2004 Oct 2 I

25. Sukkar MB, Stanley AJ, Blake AE, Hodgkin PD, Johnson PR, Armour $\mathrm{CL}$, Hughes JM: 'Proliferative' and 'synthetic' airway smooth muscle cells are overlapping populations. Immunol Cell Biol 2004, 82(5):47I-8.

26. Brown JK, Jones CA, Rooney LA, Caughey GH, Hall IP: Tryptase's potent mitogenic effects in human airway smooth muscle cells are via nonproteolytic actions. Am J Physiol Lung Cell Mol Physiol 2002, 282:L197-206.

27. Jiang $H$, Harris $M$, Rothman P: IL-4/IL-I3 signaling beyond JAK/ STAT. J Allerg Clin Immunol 2000, I 05:1063-70.

28. Tinnell SB, Jacobs-Helber SM, Sterneck E, Sawyer ST, Conrad DH STAT6, NF-kappaB and C/EBP in CD23 expression and IgE production:. Int Immunol 1998, I O( I 0): I529-38.

29. Gunt SJ, Tang DD, Saez AO: Cytoskeletal remodeling of the airway smooth muscle cell: a mechanism for adaptation to mechanical forces in the lung. Respir Physiol Neurobiol 2003, I37:151-168.

30. Hirshman CA, Zhu D, Panettieri RA, Emala CW: Actin depolymerization via beta-adrenoreceptor in airway smooth muscle cells: a novel PKA-independent pathway. Am J Physiol Cell Physiol 200I, 28 I:CI468-76.

31. Halayko AJ, Solway J: Molecular mechanisms of phenotypic plasticity in smooth muscle cells. J Appl Physiol 200I, 90:358-68.

32. Nishiyama T, Sasaki T, Takaishi K, Kato M, Yaku H, Araki K, Matsuura $Y$, Takai $Y$ : rac $p 2 I$ is involved in insulin-induced membrane ruffling and rho $\mathrm{p} 2 \mathrm{I}$ is involved in hepatocyte growth factorand 12-O-tetradecanoylphorbol-13-acetate (TPA)-induced membrane ruffling in KB cells. Mol Cell Biol 1994, I 4:2447-56.

33. Okamoto H, Takuwa N, Yokomizo T, Sugimoto N, Sakurada S, Shigematsu H, Takuwa Y: Inhibitory Regulation of Rac Activation, Membrane Ruffling, and Cell Migration by the G ProteinCoupled Sphingosine-I-Phosphate Receptor EDG5 but Not EDG I or EDG3. Mol Cell Biol 2000, 20:9247-6I.

34. Fish J, Peters S: Airway remodeling and persistent airway obstruction in asthma. J Allerg Clin Immunol 1999, I 04:509-I6.

35. Oltman U, Issa R, Sukkar MB, John M, Chung KF: Role of c-jun $\mathbf{N}$ terminal kinase in the induced release of GM-CSF, RANTES and IL-8 from human airway smooth muscle cells. $\mathrm{Br}$ Pharmacol 2003, I39:|228-34.

Publish with Biomed Central and every scientist can read your work free of charge

"BioMed Central will be the most significant development for disseminating the results of biomedical research in our lifetime. "

Sir Paul Nurse, Cancer Research UK

Your research papers will be:

- available free of charge to the entire biomedical community

- peer reviewed and published immediately upon acceptance

- cited in PubMed and archived on PubMed Central

- yours - you keep the copyright
BioMedcentral 